\title{
Suc de taronja: una experiència didàctica d'atenció a la diversitat
}

\author{
Xavier Pagés i Segarra \\ Raúl Oswaldo Senra Jimenez \\ Maria París Burguete \\ Paco París Burguete \\ IES Botànic Cavanilles, La Vall d'Uixó
}

Aprofitant la visita de les alumnes del col-legi britànic de la ciutat de Lancaster (GB) al nostre centre va sorgir la idea de fer una experiència interdisciplinar consistent a fer tots els preparatius, des de l'àmbit científic del Projecte de Diversificació Curricular (PDC) de $4 t$ d'ESO, per oferir un gotet de suc de taronja durant tres dies a l'hora del primer esbarjo.

Paraules clau: mescla, concentració, planificació, cooperativa, sedimentació

\section{Introducció}

Cal dir que als alumnes se'ls presenta el projecte com si fos una petita empresa (tant de bo ho fóra, en aquest temps on cal tirar d'imaginació per buscar-se la pataqueta!)

En el cas que ens ocupa, un quiosc dispensari de suc de taronja com el que sovint es veu al carrer o en els restaurants.

Podem parlar de suc de taronja, d'orxata, o de bolets de l'Empordà, tant se val: es tracta d'emprendre un petit negoci que connecte un sector primari (producció agrària) amb un sector secundari (manufactura del suc) i amb un de terciari (comercialització del producte), dissenyant tots els passos necessaris per activar-lo i avaluar-ne el balanç de costos i beneficis perquè siga rendible.

\section{Objectiu}

Es tracta de motivar els alumnes de 4t d'ESO (PDC), en l'estudi de distintes matèries com matemàtiques, física, química, tecnologia, plàstica i anglès, mitjançant un projecte de treball interdisciplinar al voltant de la idea de fabricar suc de taronja, aprofitant la visita d'unes alumnes de la ciutat anglesa de Lancaster.

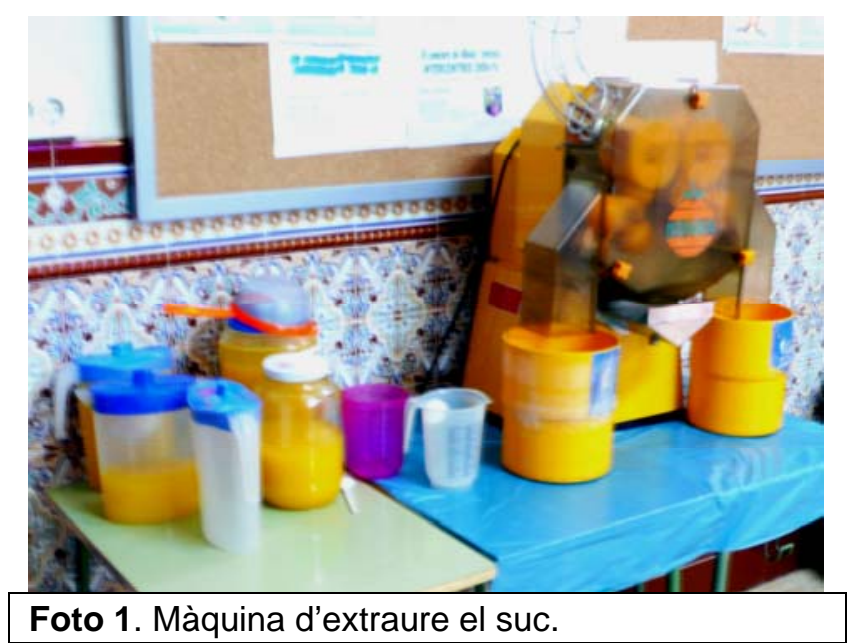

Per això els professors dels àmbits científic, lingüístic i tecnològic, així com els d'anglès i de plàstica, han treballat de forma coordinada.

\section{Preguntes motivadores inicials als alumnes:}

a) Què es necessita per a fabricar suc de taronja?

b) Qui ens pot ajudar a realitzar el projecte?

c) Quanta física i matemàtica cap en el projecte? 
d) Quanta química cap en l'experiència didàctica?

e) Quines són les propietats nutritives del suc de taronja?

f) Quines visites es podrien realitzar?

g) Com es pot publicitar, a més a més en anglès?

A continuació anirem desenvolupant les activitats realitzades al llarg de tres setmanes, en forma de resposta a les preguntes anteriors on la participació dels 12 alumnes del PDC fou força decisiva a causa de l'interès demostrat.

\section{Resum de les respostes a les preguntes motivadores inicials}

\section{a) Què es necessita per a fabricar suc de taronja?}

Evidentment necessitem taronges i una màquina per a obtenir-ne el suc. Ens hem adreçat a la Caixa rural Sant Vicent Ferrer, mitjançant una instància, sol-licitant la màquina automàtica (foto 1).

Les taronges València Late, a 0,6 € / Kg, ens les ha servit "Fruites Latorre" del mercat de la Vall d'Uixó. Estan disposat a servir-nos cada dia 15 caixes de $10 \mathrm{Kg} /$ caixa, per no tenir problemes d'emmagatzematge, ja que l'activitat es realitzarà al vestíbul del centre.

b) Qui ens pot ajudar a realitzar el projecte?

Els alumnes han preparat les instàncies adients a les institucions per a obtenir l'ajuda necessària:

- Al director del centre, informant-lo del projecte, tot i presentant-li un esborrany dels costos i beneficis de l'activitat. El cost total de la matèria prima -les taronges- fou de $239 €$.

- Al director de la Caixa Sant Vicent, sol-licitant-li ajuda en forma de màquina espremedora automàtica, gotets i taronges. La resposta de la caixa ha estat ajustada als temps de crisi: màquina i gotets sí; taronges, no!

- Al gerent de la cooperativa de taronges Vallexport sol-licitant-li permís per visitar-la.

\section{c) Quanta física i matemàtica cap en el projecte? \\ - Mesura de capacitats}

Quants $\mathrm{mL}$ de suc volem oferir en cada got? Malgrat que la seua capacitat màxima és de 125 $\mathrm{mL}$ es decideix servir-hi sols entre 60 i $90 \mathrm{~mL}$.

- Càlculs matemàtics

Quants gots de suc de taronja cal preparar cada dia? Estimant-ho en funció del nombre d'alumnes (400) s'ha considerat que només el 80 \% són partidaris de prendre el suc, resultant 320 gots al dia.

Quants quilos / dia de taronges hem d'utilitzar? Per a trobar la resposta estimativa s'ha procedit a extraure el suc d'una taronja amb una espremedora manual (foto 2).

A partir d'una mostra de 10 taronges s'ha trobat que s'obtenen 32,4 mL de suc per cada $100 \mathrm{~g}$ de taronja.

Posteriorment en tenir la màquina fou necessari rectificar l'estimació anterior, ja que el rendiment de la màquina automàtica és inferior. Només s'obtenien 20,8 $\mathrm{mL}$ per cada $100 \mathrm{~g}$ de taronja.

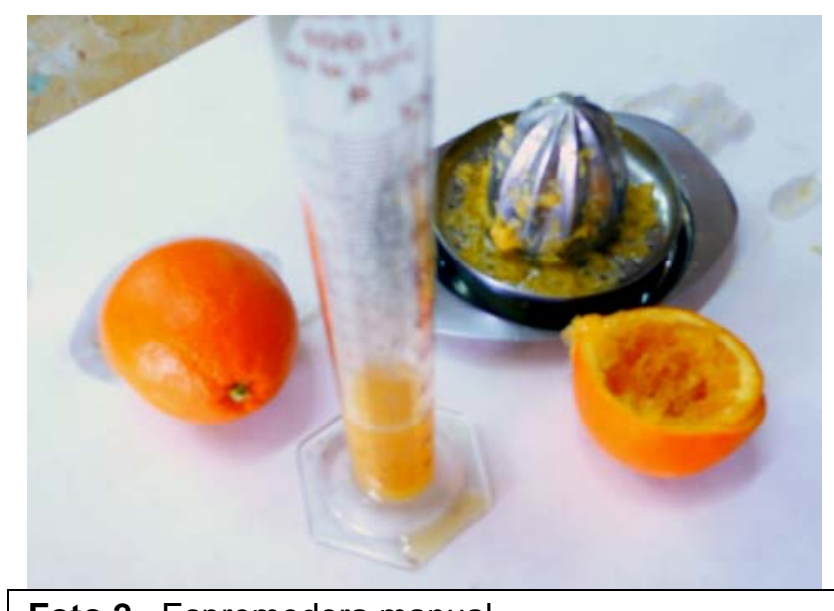

Foto 2. Espremedora manual.

Per quin procediment s'obté més rendiment?

El rendiment de l'espremedora manual, és superior al de la màquina automàtica com es pot comprovar amb les dades anteriors.

\section{Quin és el percentatge de rebuig en cada procediment?}

- Massa de rebuig amb el expremedor manual: $59,1 \mathrm{~g} / 100 \mathrm{~g}$ de taronja.

- Massa de rebuig amb la màquina: 60,1 g/ $100 \mathrm{~g}$ de taronja.

Evidentment, el procés automàtic genera més residus que el manual.

Finalment, quants kilograms de taronges es necessiten per dia, per a preparar 320 gotets amb $80 \mathrm{~mL}$ cadascun sabent que per cada $100 \mathrm{~g}$ de taronja s'obté $20,8 \mathrm{~mL}$ de suc?

Com es pot comprovar resulta $123 \mathrm{~kg} / \mathrm{dia}$.

\section{Quant costaran totes les taronges de tres dies} d'activitat a $60 \mathrm{c} € / \mathrm{Kg}$ sense IVA?

Resulta un cost total de $221 €$. 
I el cost total amb el $8 \%$ d'IVA?

Resulta un total de $239 €$.

\section{Mesura de la massa de les caixes de taronges}

Es fa amb una balança romana (foto 3). S'utilitza aquest procediment per ser la romana un instrument d'ús tradicional basat en la palanca de primer gènere.

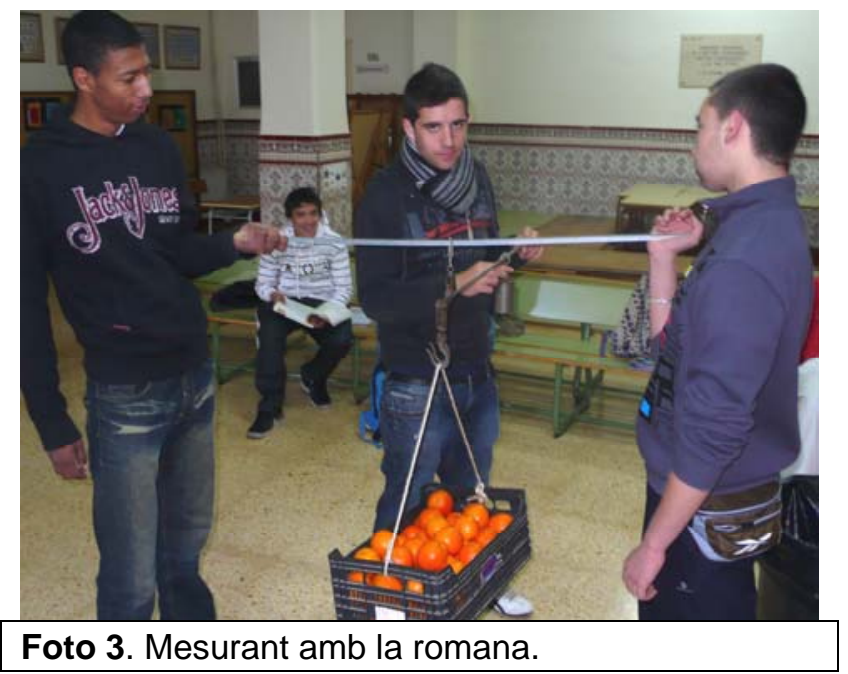

Cada caixa conté una massa de $10 \mathrm{Kg}$ de taronges, descomptant la massa de la caixa.

\section{Mesura de la densitat del suc de taronja}

S'ha trobat una densitat de $1,04 \mathrm{~g} / \mathrm{mL}$ utilitzant una balança de $0,001 \mathrm{~g}$ de sensibilitat i una proveta de $0,1 \mathrm{~mL}$ de sensibilitat. Els resultats de les mesures experimentals han estat:

$$
m=10,42 \mathrm{~g} \quad \mathrm{i} \quad \mathrm{V}=10,0 \mathrm{~mL}
$$

\section{Observació del suc de taronja:} mescla o dissolució?

Al cap d'una estona es pot comprovar que el suc de taronja és una mescla heterogènia d'unes substàncies sòlides (polpa de taronja) que sedimenten, junt amb d'altres que estan en dissolució.

\section{Separació de la polpa per filtració}

Hem pogut comprovar com el suc surt filtrat de la màquina automàtica i nosaltres encara l'hem refinat més, a l'objecte de reduir més si cap la polpa, que és origen de flatulència en certes persones.

\section{Cal-libratge de les taronges}

Amb un peu de rei hem mesurat el conducte d'admissió de la màquina automàtica i hem comprovat que les Valencia Late que hem d'utilitzar han de tenir un cal.libre inferior a $70 \mathrm{~mm}$.

\section{d) Quanta química cap en l'experiència didàctica?}

Al nivell que ens ocupa ens hem centrat en el valor del $\mathrm{pH}$ que ens ha donat un valor de 2,6 mitjançant un aparell digital. També hem comprovat la coloració rogenca que dóna al paper indicador universal.

\section{e) Quines son les propietats nutritives del suc de taronja?}

Els alumnes han investigat en la xarxa aquestes propietats, amb la qual cosa s'ha fomentat l'ús de les tecnologies de la informació i la comunicació (TIC). Per exemple aquesta pàgina.

\section{f) Quines visites es podrien realitzar?}

Cooperativa Vallexport (foto 4) i Museu de la Taronja de Borriana.

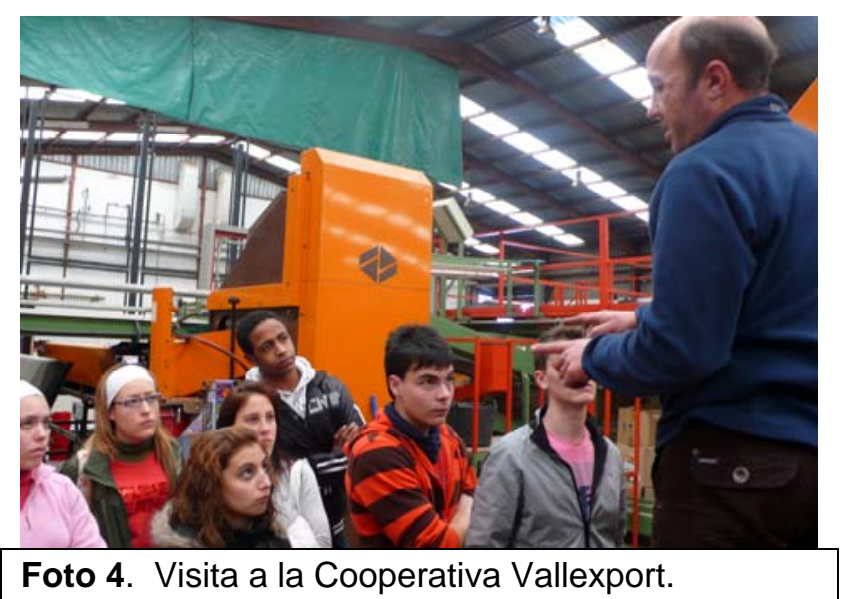

\section{h) Com és pot publicitar, a més a més en anglès?}

La participació del departament d'anglès ha contribuït a tota la tasca de comunicació en llengua anglesa (realització d'un cartell i díptic explicatiu) per a realitzar una activitat d'aplicació del coneixement de l'anglès amb les alumnes invitades de Lancaster amb frases de diàleg com per exemple:

\section{Welcome, Mr Juice}

1) Oferim suc:

Would you like some orange juice?

Good morning, a glass of juice?

Podem contestar:

Yes, thank you very much.

2) Demanem suc:

Can I have some juice?

Excuse me, can I take one?

Podem contestar:

Yes, of course. Here you are. 
La foto següent (foto 5) és una mostra del que s'ha fet en publicitat, amb col·laboració amb l'assignatura de plàstica, realitzant un concurs i seleccionant, per votació, els propis alumnes el més representatiu.

\section{Conclusió}

L'experiència ha estat un èxit des de tots els punts de vista. S'ha treballat interdisciplinàriament el projecte, com es mostra a la taula següent:

\begin{tabular}{|c|c|}
\hline MATĖRIA & ACTIVITAT \\
\hline Àmbit científic & $\begin{array}{c}\text { Matemàtiques, } \\
\text { Física, Química }\end{array}$ \\
\hline Àmbit lingüístic & $\begin{array}{c}\text { Textos: instàncies, } \\
\text { publicitat }\end{array}$ \\
\hline Àmbit tecnològic & $\begin{array}{c}\text { Automatismes } \\
\text { màquina espremedora }\end{array}$ \\
\hline Anglès & Textos en anglès \\
\hline Plàstica & Cartells publicitaris \\
\hline
\end{tabular}

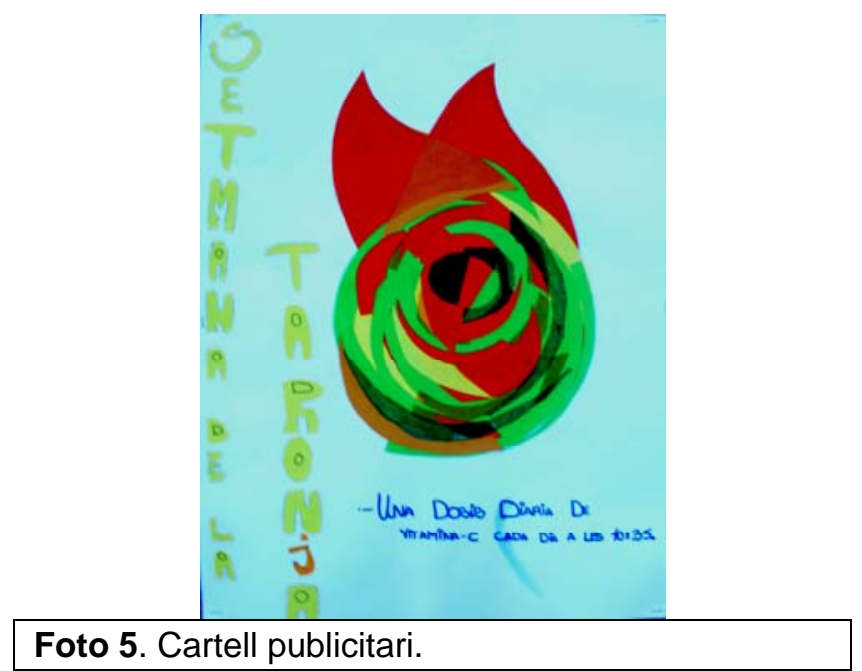

A més a més s'ha visitat una cooperativa. S'ha escrit i parlat en anglès amb les alumnes de l'intercanvi, al mateix temps que es donava a conèixer un producte de la nostra terra. Cal afegir com a darrera reflexió la necessitat de potenciar el paper de la industria conservera de sucs de taronja. El grup de 12 alumnes que hi ha participat ho ha fet amb moltíssima il-lusió. Qui sap si el dia de demà els servirà per a desenvolupar les seues pròpies iniciatives empresarials. Afegim unes instantànies que completen la visió global de l'experiència didàctica:
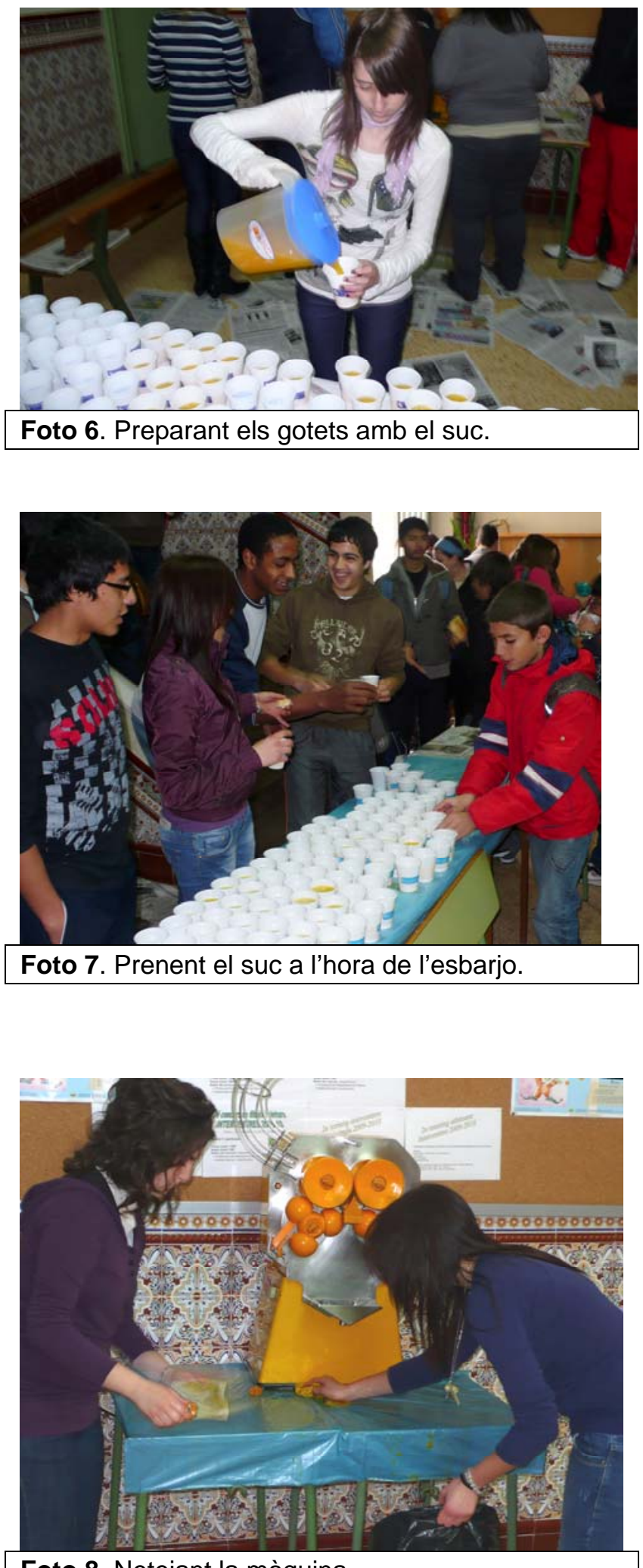

Foto 8. Netejant la màquina. 